\title{
Spatial Distribution, Population Structure, and Predatory Impact of Gelatinous Predators on Zooplankton Community in Inshore Waters off Crimean Coast of the Black Sea
}

Galina A. Finenko*, Boris E. Anninsky and Natalya A. Datzyk A.O. Kovalevsky Institute of Biology of the Southern Seas of RAS Sevastopol, Russian Federation

Received 25.05.2018, received in revised form 11.12.2020, accepted 02.03.2021, published online 19.03.2021

\begin{abstract}
The study reports the data on the distribution and predatory impact of the gelatinous macroplankton on mesozooplankton in the inshore waters of Crimea in April 2016. In the study areas, gelatinous macroplankton comprised Scyphomedusae Aurelia aurita (Linnaeus, 1758) and three ctenophore species (Mnemiopsis leidyi A. Agassiz, 1865, Beroe ovata Bruguire, 1789, and Pleurobrachia pileus (O.F. Müller, 1776). The biomass of A. aurita dominated everywhere and varied from $\sim 62$ to $330 \mathrm{~g} \cdot \mathrm{m}^{-2}$ in different areas. The largest $A$. aurita biomass was observed in the South Coast of Crimea and the smallest in Karkinitsky Bay, where the number of jellyfish was high, suggesting the predominance of small individuals in the population. The size structure of $A$. aurita population differed by region: the proportion of large animals increased from the West to the East. The abundance and biomass of M. leidyi were rather low: $0.33-1.45$ ind $\cdot \mathrm{m}^{-2}$ and $1-51.7 \mathrm{~g} \cdot \mathrm{m}^{-2}$, respectively (the exception was the position in the Kerch Strait, where $M$. leidyi abundance reached 2 ind. $\mathrm{m}^{-2}$ and biomass $126.3 \mathrm{~g} \cdot \mathrm{m}^{-2}$ ); that species occurred only at 33-45\% of the stations (the exception was Karkinitsky Bay $-17 \%$ ), with the maximum values in the South Coast of Crimea. Large, 55-70-mm, adult individuals predominated. P. pileus biomass was lower than the biomass of $A$. aurita and M. leidyi in all areas, but its abundance was much higher. The daily rations of $A$. aurita varied widely both in the entire area and from one region to another. The daily ration values correlated with the carbon content in A. aurita body. The predation pressure of $A$. aurita on zooplankton in the inshore waters of Crimea was very low and did not result in a crucial decrease in mesozooplankton abundance. The effect of $M$. leidyi, even with its low abundance and biomass, was much stronger.
\end{abstract}

(C) Siberian Federal University. All rights reserved

This work is licensed under a Creative Commons Attribution-NonCommercial 4.0 International License (CC BY-NC 4.0).

* Corresponding author E-mail address: gfinenko@gmail.com

ORCID: 0000-0002-3303-0906 (Finenko G.); 0000-0001-9614-9392 (Anninsky B.); 0000-0002-8113-8786 (Datzyk N.) 
Keywords: gelatinous zooplankton, Aurelia aurita, Mnemiopsis leidyi, Pleurobrachia pileus, abundance, biomass, daily ration, consumption.

Acknowledgements. The study was performed to fulfil the Government Assignment given to IBSS «Functional, metabolic, and toxicological aspects of the existence of aquatic organisms and their populations in biotopes with different physicochemical conditions» (R\&D reference number 121041400077-1) and the project funded by RFBR and the city of Sevastopol p_a 18-44-920022 «Response of the Black Sea pelagic system to climate change in the region (in the case study of jellyfish, ctenophores, and small pelagic fishes)».

Citation: Finenko G. A., Anninsky B.E., Datzyk N. A. Spatial distribution, population structure, and predatory impact of gelatinous predators on zooplankton community in inshore waters off Crimean coast of the Black sea. J. Sib. Fed. Univ. Biol., 2021, 14(2), 168-181. DOI: 10.17516/1997-1389-0336

\title{
Пространственное распределение,
} структура популяций желетелых хищников

и пищевой пресс на зоопланктонное сообщество

в прибрежных районах Крымского побережья

\section{Черного моря}

\author{
Г. А. Финенко, Б. Е. Аннинский, Н. А. Дацык \\ ФИЦ Институт биологии южных морей им. А.О. Ковалевского РАН \\ Российская Федеращчия, Севастополь
}

\begin{abstract}
Аннотация. Приводятся данные по распределению и хищничеству желетелого макропланктона на шельфе Крыма в апреле 2016 г. В районах исследований желетелый макропланктон был представлен сцифомедузой Aurelia aurita (Linnaeus, 1758) и тремя видами гребневиков (Mnemiopsis leidyi A. Agassiz, 1865, Beroe ovata Bruguire, 1789, Pleurobrachia pileus (O. F. Müller, 1776)). A. aurita всюду доминировала по биомассе, изменявшейся в пределах от $\sim 2$ до 1330 г·' $\mathrm{M}^{-2}$ в разных районах. Максимальная биомасса медуз A. aurita отмечена в районе Южного берега Крыма, минимальная в районе Каркинитского залива, что при высокой численности говорит о преобладании в популяции мелких животных. Размерная структура популяции A. aurita различалась по районам с увеличением доли крупных медуз с запада на восток. Гребневик M. leidyi при небольшой численности $\left(0,33-1,45\right.$ экз $\left.\cdot \mathrm{M}^{-2}\right)$ и биомассе $\left(<1-51,7 \Gamma^{\cdot} \mathrm{M}^{-2}\right)$ (исключение - станция в Керченском проливе, где численность составляла 2 экз $\cdot \mathrm{M}^{-2}$, а биомасса $\left.-126,3 \Gamma^{\cdot} \cdot \mathrm{M}^{-2}\right)$ встречался в Черном море лишь на $33-$ $45 \%$ станций (исключение - Каркинитский залив -17 \%). В популяции преобладали крупные взрослые животные 55-70 мм. Биомасса P. pileus во всех районах была ниже биомассы A. aurita и M. leidyi при значительно более высокой его численности. Суточные рационы A. aurita варьировали в широких пределах как внутри каждого района, так и от района к району. Величина суточного
\end{abstract}


рациона в отдельных районах и на всей исследованной акватории коррелировала с содержанием углерода в теле медуз. Выедание зоопланктона A. aurita на шельфе Крыма было очень низким и не приводило к кардинальному сокращению численности зоопланктона. Влияние M. leidyi, даже при его низкой численности и биомассе, было значительно выше по сравнению с медузами.

Ключевые слова: желетелый зоопланктон, Aurelia aurita, численность, биомасса, суточный рацион, выедание зоопланктона.

Благодарности. Работа подготовлена по теме государственного задания ФГБУН ФИЦ Институт биологии южных морей «Функциональные, метаболические и токсикологические аспекты существования гидробионтов и их популяций в биотопах с различным физико-химическим режимом» (Регистрационный номер 121041400077-1) и по Проекту РФФИ и г. Севастополя p_a 18-44-920022 «Отклик черноморской пелагической экосистемы на изменение климата в регионе (на примере медуз, гребневиков и мелких пелагических рыб)».

Цитирование: Финенко, Г.А. Пространственное распределение, структура популяций желетелых хищников и пищевой пресс на зоопланктонное сообщество в прибрежных районах Крымского побережья Черного моря / Г. А. Финенко, Б. Е. Аннинский, Н. А. Дацык // Журн. Сиб. федер. ун-та. Биология, 2021. 14(2). С. 168-181. DOI: 10.17516/1997-1389-0336

\section{Введение}

Потенциальное увеличение размеров популяций желетелых в морях связано как с климатическими изменениями, так и с человеческой деятельностью, приводящей к изменению среды обитания: рыболовство, потепление океана, гипоксия, модификация мест обитания, эвтрофикация и интродукция новых видов (Purcell et al., 2007; Richardson et al., 2009; Purcell, 2012). Индикатором негативного сдвига в состоянии пелагической экосистемы является переход от доминирования рыб к желетелым, что изменяет структуру пищевой цепи и пути передачи вещества и энергии в экосистемах. Желетелые быстро реагируют на пространственные и временные изменения в районах высокой продуктивности благодаря их высокой скорости питания и роста (Finenko et al., 2009) и в периоды голодания до 3-4 недель способны выживать, уменьшаясь в размерах (Anninsky et al., 2005).

Медуза Aurelia aurita (Linnaeus, 1758) и три вида гребневиков (Mnemiopsis leidyi
A. Agassiz, 1865, Beroe ovata Bruguire, 1789, Pleurobrachia pileus (O.F. Müller, 1776)), два из которых (M. leidyi, B. ovata) являются вселенцами, широко распространенные в Черном море виды желетелых. Будучи активными хищниками, они имеют (кроме B. ovata) сходный пищевой спектр, практически совпадающий с пищевым спектром личинок планктоноядных рыб, в течение большей части своего жизненного цикла потребляя мезозоопланктон. Массовое развитие этих видов последовательно во времени: пик численности A. aurita наблюдается в позднезимний весенний период (март - май), M. leidyi - в середине лета (июль - август), а пик B. ovata, питающегося M. leidyi, связан с достижением его максимальной численности и варьирует от года к году. Таким образом, влияние как на видовой состав, так и на обилие мезозоопланктона за счет потребления желетелыми может осуществляться в течение длительного периода и зависит от интенсивности их хищничества и количественного развития 
видовых популяций. Антропогенные и климатические факторы определяют развитие популяций желетелых, претерпевающее значительную вариабельность во времени и пространстве. Проведение долговременных регулярных наблюдений за количественным развитием их популяций дает основу для оценки влияния различных факторов на их состояние, пищевой пресс на планктонное сообщество, пищевую обеспеченность планктоноядных рыб и, соответственно, на функционирование пелагической экосистемы в целом.

Работа является частью мониторинга за состоянием экосистемы прибрежных и открытых вод Черного моря у берегов Крыма, проводимого Институтом морских биологических исследований РАН с 2016 г. Основной целью нашего исследования стала оценка состояния популяций желетелого макрозоопланктона и его пищевой пресс на зоопланктонное сообщество в прибрежных районах Черного моря в весенний период.

В задачи работы входило:

- изучить пространственное распределение и структуру популяций желетелых хищников в шельфовых районах Черного моря в весенний период;
- исследовать пищевой спектр массовых видов желетелых и скорость потребления пищи;

- оценить выедание зоопланктона этими видами.

\section{Материал и методы}

Район исследования,

сбор и обработка материала

Исследования проводили в 84-м рейcе НИС «Профессор Водяницкий» с 19 по 27 апреля 2016 г. на 22 станциях в прибрежных районах Крымского полуострова Черного моря и Керченского пролива (координаты $45^{\circ} 41^{\prime}-44^{\circ} 18^{\prime} \mathrm{N}, 36^{\circ} 25^{\prime}-32^{\circ} 24^{\prime} \mathrm{E}$ ) (рис. 1). Вся изученная акватория была разделена на пять районов согласно районированию В.А. Водяницкого (1949): 1 - район Каркинитского залива (ст. 3, 4, 5), 2 - Евпаторийско-Севастопольский район (ст. 1, 2, 7-9), 3 - район Южного берега Крыма (ст. 11-19, 27), 4 - Феодосийский район (ст. 20, 21, 26), 5 - район Керченского пролива (ст. 22).

Все станции были расположены на шельфе с глубинами от 10 до 150 м (район внутреннего и внешнего шельфов). Температура воды на поверхности на отдельных станциях

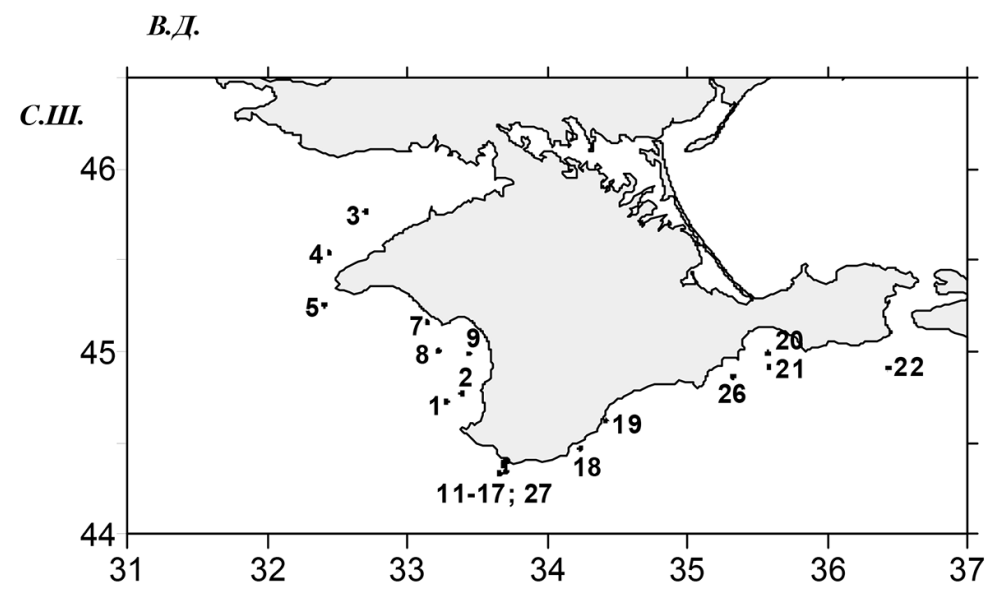

Рис. 1. Карта станций отбора проб в 84-м рейсе НИС «Профессор Водяницкий»

Fig. 1. Map of sampling sites during the $84^{\text {th }}$ expedition of RV «Professor Vodyanitskii» 
в Черном море изменялась от 10,1 до $11,9{ }^{\circ} \mathrm{C}$, соленость - от 18,18 до 18,38 \%, в Керченском проливе температура достигала $13,95^{\circ} \mathrm{C}$, соленость снижалась до 13,59 \%. Глубина видимости диска Секки в Черном море варьировала от 7 до 20 м.

Для сбора желетелого макропланктона использовали модифицированную сеть Богорова-Расса (БР), диаметр входного отверстия 80 см, ячея 300 мкм, ею производили вертикальные траления (от 1 до 4 на станции) от 3 м от дна до поверхности. Пробы обрабатывали немедленно после их отбора. Диаметр купола медуз A. aurita (расстояние между статоцистами) и орально-аборальную длину M. leidyi измеряли с точностью до 1 мм в момент максимального расслабления особей на градуированной стеклянной пластине. Массу тела рассчитывали, используя ранее установленные линейно-весовые соотношения (Datsyk et al., 2016). Наличие в пробах мелких желетелых организмов и их стадий контролировали под микроскопом при увеличении $8 \times 2$.

\section{Исследование питания желетельх}

Для изучения спектра и интенсивности питания желетелых хищников в море всех выловленных особей просматривали в лаборатории под микроскопом сразу после вылова. Состав пищи в гастральной полости животных по возможности определяли до вида и стадии развития. Суточный рацион медуз и гребневиков $\left(R\right.$, мг экз $3^{-1}$ сут $\left.^{-1}\right)$ рассчитывали по формуле

$$
\mathrm{R}=\mathrm{B}_{\mathrm{pr}} \times \mathrm{DT}^{-1} \times 24,
$$

где $\mathrm{B}_{\mathrm{pr}}$ - биомасса зоопланктона в гастральной полости хищника (мг·экз $\left.{ }^{-1}\right)$; DT - время переваривания зоопланктона (ч). Для перехода от численности мезозоопланктона к еди- ницам биомассы использовали известные для черноморских видов размерно-весовые соотношения (Петипа, 1957). В расчетах суточных рационов медуз было учтено, что время переваривания является функцией веса хищника, температуры и биомассы пищи в гастральной полости $\mathrm{DT}=\mathrm{f}\left(\mathrm{WW}, \mathrm{t}, \mathrm{B}_{\mathrm{pr}}\right)$, где $\mathrm{WW}$ - сырая масса тела животных (г) и $\mathrm{t}$ - температура воды в море соответственно. Эмпирическая формула для расчета времени переваривания у медуз имела вид

$$
\mathrm{DT}=1,81 \mathrm{~B}_{\mathrm{pr}}^{0,122} \mathrm{WW}^{-0,193} \mathrm{k}_{\mathrm{t}} \mathrm{k}_{\mathrm{sp}},
$$

где $\mathrm{B}_{\mathrm{pr}}$ - биомасса жертв в гастральной полости (мкг·экз-1); $\mathrm{k}_{\mathrm{t}}$ - температурная поправка, равная 2,40, для пересчета времени переваривания рачкового зоопланктона при $20{ }^{\circ} \mathrm{C}$ к $11{ }^{\circ} \mathrm{C}$ (средняя температура на станциях в период исследования); $\mathrm{k}_{\mathrm{sp}}(=2,67)$ - поправка на увеличение времени переваривания велигеров Bivalvia по сравнению с рачковым зоопланктоном (Hansson et al., 2005). Последнюю поправку не вводили, когда крупные $A$. aurita (больше 150 мм) содержали в гастральной полости не более 5 велигеров. В этих случаях время переваривания велигеров приравнивалось ко времени переваривания рачкового зоопланктона. Время переваривания пищи M. leidyi было рассчитано по данным (Финенко и др., 2005) с учетом температурной поправки.

Пищевой пресс популяций $A$. aurita и M. leidyi на мезопланктон оценивали, основываясь на соотношениях между величи-

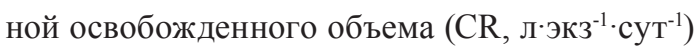
с диаметром (D, мм) или сырым весом животных (WW, г), а также на численности их популяций $\left(\mathrm{N}\right.$, экз· $\left.\mathrm{M}^{-3}\right)$ :

Aurelia aurita: $\mathrm{CR}_{\text {ind }}=0,0073 \mathrm{D}^{2,1}$ (Møller and Riisgard, 2007) $\quad \mathrm{T}=15^{\circ} \mathrm{C}$ 
Mnemiopsis leidyi: $\mathrm{CR}_{\text {ind }}=0,321 \mathrm{WW}^{1,288}$

(Финенко и др., 2011) $\quad \mathrm{T}=20^{\circ} \mathrm{C}$

$$
\mathrm{CR}_{\text {pop }}=\mathrm{CR}_{\text {ind }} \mathrm{N} / 1000 \mathrm{M}^{3} \mathrm{M}^{-3} \cdot \mathrm{cys}^{-1}
$$

Время полужизни зоопланктона рассчитывали по уравнению

$$
\mathrm{T}=\ln 2 / \mathrm{CR}_{\mathrm{pop}} \text { (Hansson et al., 2005) }
$$

Минимальные пищевые потребности A. aurita (необходимое количество пищи для компенсации дыхательных потребностей) оценивали по формуле

$$
\mathrm{Q}=0,00936 \mathrm{WW}^{0,84} \times 0,535 \times \mathrm{k}_{\mathrm{t}} \times 24,
$$

где Q - скорость дыхания A. aurita, мг С·эк $3^{-1}$ сут $^{-1} ; \mathrm{WW}$ - сырой вес, г; $0,535-$ переходный коэффициент от миллилитров $\mathrm{O}_{2}$ к миллиграммам $\mathrm{C} ; \mathrm{k}_{\mathrm{t}}$ - температурная поправка для перехода от $20{ }^{\circ} \mathrm{C}$ к наблюдаемой температуре (Anninsky, 2009).

При оценке величин рационов в углероде было принято, что соотношение сухой : сырой вес зоопланктона равно 0,1 , соотношение C : сухой вес $=0,4$, для $A$. aurita и $M$. leidyi сухой : сырой вес $=0,02$, содержание $\mathrm{C}-0,04$ сухого веса (Аннинский и др., 2011; Finenko, Romanova, 2000).

Исследование питания медуз проводили на 22 станциях, M. leidyi - на 14 станциях, включающих 3-10 станций для медуз и 2-5 станций для гребневиков в каждом районе.

Всего исследовано 311 экз. A. aurita и 15 экз. M. leidyi. Диаметр купола медуз колебался в пределах 5-250 мм, сырой вес-0,006741,5 г, содержание углерода - 0,006-75 мг С·экз ${ }^{-1}$. Соответственно, орально-аборальная длина M. leidyi составляла 19-80 мм, сырой вес - 2,0-71,8 г, содержание углерода - 0,0655,6 мг С·экз ${ }^{-1}$.
Статистическая обработка материалов была проведена с использованием программ Excel и Grafer. Во всех случаях приведены средние величины \pm ошибка средней (SE). При сравнении средних величин использовали критерий Стьюдента.

\section{Результаты}

Количественное развитие и структура популяций желетелых

В период исследования макрозоопланктон был представлен одним видом медуз A. aurita и тремя видами гребневиков: M. leidyi, P. pileus, B. ovata.

A. aurita и P. pileus были отмечены практически на всех станциях, M. leidyi-значительно реже (65 \%) и B. ovata - лишь на одной станции. Распределение медуз было неоднородным с высокими величинами численности в районе Каркинитского залива и Южного берега Крыма и низкими - в Феодосийском районе (табл. 1). Величины численности достоверно различаются по районам $(\mathrm{p}<0,01)$, за исключением различий между Евпаторийско-Севастопольским и Феодосийским районами ( $>>0,5)$; биомассы здесь были близки между собой и занимали среднее положение в ряду исследованных районов. Максимальная биомасса $A$. aurita отмечена в районе Южного берега Крыма, минимальная - в районе Каркинитского залива, что при высокой численности говорит о преобладании в популяции мелких животных.

Размерная структура популяции A. aurita значительно различалась: в Каркинитском заливе около 95 \% медуз не превышали 50 мм, при этом до $40 \%$ популяции составляли мелкие медузы нового поколения с диаметром купола меньше 10 мм. По мере продвижения на восток доля животных размером до 50 мм снижалась (с $60 \%$ в ЕвпаторийскоСевастопольском регионе до $\sim 18$ \% в Феодо- 
Таблица 1. Численность и биомасса трех видов желетелых по районам в весенний период 2016 г. Среднее $\pm \mathrm{SE}$

Table 1. Abundance and biomass of three gelatinous species by the regions in spring 2016. Mean $\pm \mathrm{SE}$

\begin{tabular}{|c|c|c|c|c|c|c|}
\hline \multirow{2}{*}{ Район } & \multicolumn{2}{|c|}{ Aurelia aurita } & \multicolumn{2}{|c|}{ Mnemiopsis leidyi } & \multicolumn{2}{|c|}{ Pleurobrachia pileus } \\
\hline & $\mathrm{N}$ эк ${ }^{\cdot} \mathrm{M}^{-2}$ & $\mathrm{~B} \Gamma \cdot \mathrm{M}^{-2}$ & $\mathrm{~N}$ экз $\mathrm{M}^{-2}$ & $\mathrm{~B} \Gamma \cdot \mathrm{M}^{-2}$ & $\mathrm{~N}$ эк $3^{\cdot} \mathrm{M}^{-2}$ & $\mathrm{~B} \Gamma \cdot \mathrm{M}^{-2}$ \\
\hline Каркинитский залив & $36,5 \pm 17,4$ & $61,9 \pm 38,1$ & $0,33 \pm 0,37$ & $0,7 \pm 0,7$ & $20,7 \pm 3,9$ & $5,7 \pm 1,7$ \\
\hline Евпаторийско-Севастопольский & $19,4 \pm 5,9$ & $432,7 \pm 130,5$ & $1,45 \pm 0,64$ & $48,0 \pm 18,4$ & $28,9 \pm 10,9$ & $6,5 \pm 2,6$ \\
\hline Южный берег & $33,8 \pm 8,8$ & $1331,1 \pm 365,7$ & $1,27 \pm 0,36$ & $51,7 \pm 17,5$ & $52,7 \pm 10,0$ & $15,2 \pm 4,6$ \\
\hline Феодосийский & $7,5 \pm 3,2$ & $612,2 \pm 500,4$ & $1,00 \pm 0,75$ & $32,8 \pm 23,2$ & $36,8 \pm 7,5$ & $6,6 \pm 1,5$ \\
\hline Керченский пролив & 0 & 0 & 2,00 & 126,3 & 8,0 & 3,2 \\
\hline
\end{tabular}

сийском) при возрастании доли крупных медуз прошлогодней генерации (более 200 мм).

Численность и биомасса M. leidyi в период исследования были крайне низки и варьировали по районам в пределах $0,33 \pm 0,37$ и $1,45 \pm 0,64$ экз $\mathrm{M}^{-2}$ (Каркинитский залив и Евпаторийско-Севастопольский район соответственно) и $0,67 \pm 0,73$ (Каркинитский залив) $-51,7 \pm 17,5 \Gamma^{\cdot} \mathrm{M}^{-2}$ (район Южного берега Крыма соответственно). В районе Керченского пролива они были несколько выше. Величины биомасс и частота присутствия гребневика на станциях в разных районах были близки, за исключением Каркинитского залива (здесь M. leidyi присутствовал на $17 \%$ станций против 33-45 \% - в других исследованных районах). Преобладающей размерной группой в популяции во всех районах были взрослые половозрелые животные 55-70 мм (70-100\%).

$$
\text { Как указывалось выше, }
$$

B. ovata присутствовал лишь на одной станции в Евпаторийско-Севастопольском районе с численностью $2,7 \pm 2,2$ экз $\mathrm{M}^{-2}$ и биомассой $5,5 \pm 3,7 \Gamma^{\cdot} \mathrm{M}^{-2}$ (среднее из трех ловов). Популяция была представлена неполовозрелыми животными до 30 мм длиной.

Холодноводный гребневик $P$. pileus был обнаружен в планктоне повсеместно с минимальной численностью и биомас- сой $20,7 \pm 3,9$ экз ${ }^{\cdot} \mathrm{M}^{-2}$ и $5,7 \pm 1,7 \Gamma^{\cdot} \mathrm{M}^{-2}$ в районе Каркинитского залива и максимальной $52,7 \pm 10,0$ экз ${ }^{\cdot} \mathrm{M}^{-2}$ и $15,2 \pm 4,6 \Gamma^{\cdot} \mathrm{M}^{-2}$ в районе Южного берега Крыма с достоверной $(\mathrm{p}<0,01)$ разницей между районами (в Керченском проливе была лишь одна станция, не позволяющая оценить достоверность различий). Промежуточными, относительно равными значениями численности характеризовались станции двух других районов ( $<<0,05)$. Так как $P$. pileus - глубоководный вид, то такое распределение объясняется тем, что шельфы юго-восточной и западной части Крыма менее глубокие, чем южное побережье Крыма. В целом, биомасса $P$. pileus во всех районах была значительно ниже биомассы $A$. aurita и M. leidyi при более высокой его численности.

Во всех исследуемых районах в популяции P. pileus преобладали животные диаметром до 10 мм, за исключением Феодосийского района, где обе размерные группы $(<10$ и 11-20 мм) присутствовали в равных количествах.

Коэффициенты вариации (Cv) численности и биомассы трех видов желетелых несколько различались: наиболее вариабельными были величины у M. leidyi $(105,4-$ $244,9 \%$ по численности и 121,7-244,9 \% по биомассе), в то время как минимальные 
Таблица 2. Коэффициенты вариации (Cv) численности (Ч) и биомассы (Б) желетелых в прибрежных районах Черного моря в апреле 2016 г.

Table 2. The coefficients of variation (Cv) of abundance (Ч) and biomass (Б) of gelatinous zooplankton in the Black Sea inshore areas in April 2016

\begin{tabular}{|l|c|c|c|c|c|c|c|c|}
\hline \multirow{2}{*}{\begin{tabular}{c}
\multirow{2}{*}{ Вид } \\
\cline { 2 - 11 }
\end{tabular}} & \multicolumn{2}{|c|}{$\begin{array}{c}\text { Каркинитский } \\
\text { залив }\end{array}$} & \multicolumn{2}{c|}{$\begin{array}{c}\text { Евпаторийско- } \\
\text { Севастопольский }\end{array}$} & \multicolumn{2}{c|}{ Южный берег } & \multicolumn{2}{c|}{ Феодосийский } \\
\cline { 2 - 11 } & Ч & Б & Ч & Б & Ч & Б & Ч & Б \\
\hline Aurelia aurita & 106,8 & 137,7 & 84,2 & 127,1 & 100,6 & 106,4 & 96,8 & 182,8 \\
\hline Mnemiopsis leidyi & 244,9 & 244,9 & 138,7 & 121,7 & 105,4 & 126,3 & 167,3 & 158,1 \\
\hline Pleurobrachia pileus & 42,2 & 65,6 & 119,1 & 128,2 & 70,7 & 114,1 & 45,4 & 50,5 \\
\hline
\end{tabular}

величины - 42,2-119,1 и 50,5-128,2 \% соответственно - наблюдались у P. pileus (табл. 2).

\section{Исследования питания A. aurita}

Из исследованных 311 экз. практически все (исключение 3 экз.) содержали пищу в гастральной полости. Пищевой спектр медуз был достаточно однообразен. Основу пищевого комка составляли Acartia sp. (A. clausi + A. tonsa) и велигеры бивальвий, суммарная доля которых изменялась от $~ 80$ до 95 \% общего количества жертв в гастральной полости с максимальной величиной в ЕвпаторийскоСевастопольском районе (табл. 3). Количественный состав этих жертв различался по районам: в Феодосийском районе до 82 \% составляли велигеры двустворчатых моллюсков и только около $9 \%$ - Acartia sp., что достоверно отличало его от других районов ( $<<0,01)$, где доля велигеров в среднем была 52-54\%.

Судя по величине удельного содержания жертв в пищевом комке медуз, интенсивность потребления Acartia sp. и велигеров Bivalvia снижается с запада на восток (табл. 3). Средние суточные рационы в популяции A. aurita изменялись в широких пределах как внутри каждого района, так и от района к району (табл. 3), что объясняется различиями в размерной структуре субпопуляций медуз по районам. Величина суточного рациона как в отдельных районах, так и на всей исследо-

Таблица 3. Доля от общей численности отдельных видов жертв в гастральной полости, удельное содержание в пищевом комке $\left(\mathrm{B}_{\mathrm{pr}} / \mathrm{WW}\right.$, мг $\left.\Gamma^{-1}\right)$ и суточные рационы A. aurita в шельфовых районах Черного моря в апреле 2016 г. В скобках - среднее количество жертв в гастральной полости

Table 3. Proportions in the total abundance of selected prey species in gastric cavity, specific content in the food ball $\left(\mathrm{B}_{\mathrm{pr}} / \mathrm{WW}, \mathrm{mg} \cdot \mathrm{g}^{-1}\right)$, and daily rations of $A$. aurita in the Black Sea inshore areas in April 2016. In parenthesis is average number of prey in gastric cavity.

\begin{tabular}{|c|c|c|c|c|c|c|}
\hline \multirow{2}{*}{ Район } & \multicolumn{2}{|c|}{ \% в гастральной полости } & \multicolumn{2}{|c|}{$\begin{array}{c}\text { Удельное содержание } \\
\text { в пищевом комке }\end{array}$} & \multicolumn{2}{|c|}{ Суточные рационы } \\
\hline & Acartia sp. & $\begin{array}{c}\text { Велигеры } \\
\text { Bivalvia }\end{array}$ & Acartia sp. & $\begin{array}{c}\text { Велигеры } \\
\text { Bivalvia }\end{array}$ & 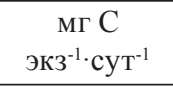 & \% С тела \\
\hline Каркинитский залив & $33,7(2,7)$ & $52,1(9,8)$ & $0,555 \pm 0,138$ & $0,069 \pm 0,035$ & $0,001-0,050$ & $0,13-10,28$ \\
\hline $\begin{array}{l}\text { Евпаторийско- } \\
\text { Севастопольский }\end{array}$ & $43,7(8,2)$ & $51,6(16,0)$ & $0,107 \pm 0,024$ & $0,060 \pm 0,046$ & $0,003-1,260$ & $0,13-11,94$ \\
\hline Южный берег Крыма & $25,3(3,6)$ & $54,1(6,6)$ & $0,031 \pm 0,010$ & $0,005 \pm 0,002$ & $0,010-0,226$ & $0,01-5,95$ \\
\hline Феодосийский & $9,3(1,8)$ & $82(9,7)$ & $0,006 \pm 0,002$ & $0,005 \pm 0,002$ & $0,003-0,049$ & $0,13-0,77$ \\
\hline
\end{tabular}


ванной акватории была связана с содержанием углерода в теле медуз (табл. 4) с высокой степенью корреляции между рассматриваемыми величинами.

Сравнение количества потребленной животными пищи $\left(\mathrm{R}, \mathrm{M \Gamma}^{\cdot} \mathrm{C}\right.$ экз $\left.{ }^{-1} \mathrm{cyT}^{-1}\right)$ c минимальными пищевыми потребностями, рассчитанными по скорости дыхания $\left(\mathrm{Q}\right.$, мг $\mathrm{C}$ эк $\left.^{-1} \cdot \mathrm{cyт}^{-1}\right)$, показали, что наиболее обеспеченной пищей была субпопуляция животных в Каркинитском заливе и Евпаторийско-Севастопольском регионе $(\mathrm{R} / \mathrm{Q}=0,72 \pm 0,07$ и $0,82 \pm 0,10$ соответственно), в районе Южного берега и Феодосии она испытывала значительный недостаток пищи $(\mathrm{R} / \mathrm{Q}=0,18 \pm 0,02$ и $0,12 \pm 0,03$ соответственно). Это свидетельствует о невозможности медуз в весенний период удовлетворить пищевые потребности исключительно за счет мезозоопланктона.

Рассчитанная на основе численности популяции медуз и величин суточных рационов скорость потребления мезозоопланктона субпопуляциями медуз в разных районах значительно различалась (табл. 5). Определяющим фактором оказалась индивидуальная интенсивность питания: средний суточный рацион особи в Евпаторийско-Севастопольском районе намного превышал рацион в других районах, что, по-видимому, связано как с ре-

Таблица 4. Параметры уравнения $\mathrm{R}=\mathrm{a} \cdot \mathrm{C}^{\mathrm{b}}$ зависимости суточного рациона $\left(\mathrm{R}\right.$, мг $\mathrm{C}$ экз $^{-1} \cdot$ сут $\left.^{-1}\right)$ от содержания углерода в теле медуз $\left(\mathrm{C}\right.$, мг·эк-1 $\left.{ }^{-1}\right)$ в исследованных районах Черного моря в апреле 2016 г., $\mathrm{n}$ - число измерений, $\mathrm{r}$ - коэффициент корреляции

Table 4. The parameters of equation $\mathrm{R}=\mathrm{a} \cdot \mathrm{C}^{\mathrm{b}}$ of the effect of carbon content in jellyfish body $\left(\mathrm{C}, \mathrm{mg} \cdot \mathrm{ind}^{-1}\right)$ on daily ration $\left(\mathrm{R}, \mathrm{mg} \mathrm{C}\right.$ ind $\left.^{-1} \cdot \mathrm{day}^{-1}\right)$ in the study areas of the Black Sea in April 2016. $\mathrm{n}$ is the number of measurements, $\mathrm{r}$ is correlation coefficient

\begin{tabular}{|l|c|c|c|c|}
\hline \multicolumn{1}{|c|}{ Район } & $\mathrm{n}$ & $\mathrm{a}$ & $\mathrm{b}$ & $\mathrm{r}$ \\
\hline Каркинитский залив & 18 & 0,017 & 0,672 & 0,875 \\
\hline Евпаторийско-Севастопольский & 26 & 0,034 & 0,625 & 0,791 \\
\hline Южный берег Крыма & 20 & 0,010 & 0,494 & 0,556 \\
\hline Все районы & 80 & 0,017 & 0,512 & 0,662 \\
\hline
\end{tabular}

Таблица 5. Потребление зоопланктона популяцией A. aurita в шельфовых районах Черного моря в апреле 2016 г. $\mathrm{R}_{\text {ind }}$ - суточный рацион особи, мг C·экз ${ }^{-1} \cdot$ сут $^{-1}, \mathrm{R}_{\text {pop }}-$ суточный рацион популяции, мг $\mathrm{C} \cdot$ сут $^{-1} \cdot \mathrm{M}^{-2}$, $\mathrm{R}_{1 \text { рор }}-$ суточный рацион популяции, мг сырого веса сут ${ }^{-1} \cdot \mathrm{M}^{-2}$

Table 5. The rate of consumption of zooplankton by A. aurita population in the Black Sea inshore waters in April 2016. $\mathrm{R}_{\text {ind }}$ is individual daily ration, $\mathrm{mgC} \cdot \mathrm{ind}^{-1} \cdot \mathrm{day}^{-1}, \mathrm{R}_{\mathrm{pop}}-$ population daily ration, $\mathrm{mgC} \cdot \mathrm{day}^{-1} \cdot \mathrm{m}^{-2}, \mathrm{R}_{1 \text { pop }}-$ population daily ration, $\mathrm{mg}$ wet weight $\mathrm{day}^{-1} \cdot \mathrm{m}^{-2}$

\begin{tabular}{|l|c|c|c|}
\hline \multicolumn{1}{|c|}{ Район } & $\mathrm{R}_{\text {ind }}$ & $\mathrm{R}_{\text {pop }}$ & $\mathrm{R}_{1 \text { pop }}$ \\
\hline Каркинитский залив & $0,010 \pm 0,003$ & $0,20 \pm 0,06$ & $4,92 \pm 1,60$ \\
\hline $\begin{array}{l}\text { Евпаторийско-Севастопольский } \\
\text { район }\end{array}$ & $0,180 \pm 0,051$ & $1,82 \pm 0,90$ & $45,45 \pm 22,41$ \\
\hline Южный берег Крыма & $0,050 \pm 0,010$ & $0,56 \pm 0,07$ & $14,11 \pm 1,70$ \\
\hline Феодосийский район & $0,030 \pm 0,010$ & $0,13 \pm 0,09$ & $3,29 \pm 2,21$ \\
\hline
\end{tabular}


гиональными особенностями пищевых условий, так и с размерным составом популяции.

Время полужизни зоопланктона при потреблении аурелией изменялось от 170,2 $\pm 60,8$ до $1140,9 \pm 418,3$ сут в исследуемых районах, что намного больше времени генерации основной пищи - копепод (50,4 сут при температуре наблюдений), т. е. популяция $A$. aurita в весенний период 2016 г. не могла контролировать биомассу зоопланктона в исследованных районах Черного моря. Нужно отметить, что наибольший пресс на зоопланктон оказывала популяция медуз в районе Южного берега Крыма, хотя во всех исследованных районах он был очень низок и не приводил к кардинальному сокращению численности зоопланктонного сообщества.

\section{Исследования питания Mnemiopsis leidyi}

Так как численность M. leidyi в море в это время была низка, питание было проанализировано лишь у 15 экз., представлявших собой взрослых животных с орально-аборальной длиной 19-80 мм. В каждом из районов было исследовано по 1-2 экз., поэтому особенности питания мнемиопсиса в шельфовой зоне Черного моря будут анализироваться без деления на районы.

Основные пищевые объекты - различные стадии рачкового зоопланктона (Acartia sp., Pseudocalanus elongatus (Bradi, 1865), Paracalanus parvus (Claus, 1863), Pleopis polyphemoides (Leuckart, 1859), Calanus euxinus (Hulsemann, 1991)) и велигеры бивальвий. Количество жертв в гастральной полости изменялось от 1 до 36 экз. с преобладанием по численности Acartia sp. (от 20 до $100 \%$ общего количества). В силу того, что размерный состав популяции всех районах был достаточно однородным, абсолютные суточные рационы гребневиков, так же как величины удельных рационов, изменялись в узких пределах - от 0,0034 до 0,0391 мг С экз ${ }^{-1}$ сут $^{-1}$ и от 0,1 до $1,5 \%$ С тела (исключение - 19 мм гребневики с удельным суточным рационом 53,3 \%), что, безусловно, значительно ниже их минимальных пищевых потребностей в данных температурных условиях.

Время полужизни зоопланктона при потреблении мнемиопсисом на отдельных станциях широко варьировало от 0,2 до 441 сут (среднее $46,0 \pm 32,2$ ) при относительно небольшой вариабельности численности и размерной структуры субпопуляций, что еще раз свидетельствует о больших различиях в интенсивности питания животных по районам. Как следует из этих данных, влияние M. leidyi на зоопланктонное сообщество даже при его низкой численности и биомассе было значительно выше по сравнению с A. aurita.

\section{Обсуждение}

Многолетний мониторинг развития популяции A. aurita, проводившийся на шельфе у Севастополя, позволил выявить сезонную динамику и оценить хищнический пресс медуз на зоопланктонное сообщество в 20032014 гг. (Аннинский и др., 2011). Максимальной биомассы медузы достигают в первой половине года (май - июнь). В 2003-2008 гг. она составляла 200-300 Г· $\mathrm{M}^{-2}$, в 2009-2010 гг. достигла 1000 и 1800 г· $\mathrm{M}^{-2}$ (Аболмасова и др., 2012). Большая часть популяции в это время представлена медузами максимального размера (150-230 мм). Доля питающихся особей в популяции также максимальна в поздневесенний - раннелетний период.

Исходя из этого, величины численности и биомассы медуз в апреле 2016 г. в исследованных районах, приведенные нами, можно рассматривать как близкие к максимальным для года. В целом, нужно отметить преобладание медуз в макропланктоне в изученных шельфовых районах Черного моря в исследуе- 
мый период. Биомасса их намного превышала биомассу других видов желетелых и достигала более $1300 \Gamma^{*} \mathrm{M}^{-2}$ в районе Южного берега Крыма. Такие же высокие величины биомассы A. aurita наблюдались в этом районе в январе - феврале 2016 г. (Финенко и др., 2016) и даже превышали их в мае 2013 г. (Datsyk et al., 2016). Таким образом, на основе мониторинговых наблюдений в шельфовой зоне у Севастополя, а также проведенных исследований 2013-2016 гг. на шельфе Крыма можно говорить о возрастании биомассы медуз в последние годы по сравнению с началом 2000-х, когда биомасса медуз в период ее максимального развития в шельфовых районах составляла 200-300 г’-2 (Аннинский и др., 2011). Плотность популяции M. leidyi в прибрежных районах, напротив, снизилась. Средняя плотность популяции в прибрежных районах Черного моря у Севастополя в 2004-2009 гг. составляла 198,2 \pm 43,7, в 2010-2014 гг. $54,5 \pm 14,0$ экз $\cdot \mathrm{M}^{-2}$ (Finenko et al., 2018).

Массовое появление в планктоне медуз новой генерации приходится, как правило, на весенний период: апрель - май. Интенсивное обновление популяции A. aurita началось в западном районе (Каркинитский залив), где преобладали медузы менее 10 мм в диаметре, что говорит об интенсивном выходе эфир и превращении их в молодые особи в этом районе. По мере продвижения на восток доля молодых животных новой генерации в популяции снижалась, и в районе Феодосии они полностью отсутствовали. Все станции в западном и восточном районах находились на внутреннем шельфе с глубинами не более 50 м и температурой около $11^{\circ} \mathrm{C}$, однако различались по трофическому статусу: если на западе большая часть черноморских поверхностных вод у берегов Крыма в апреле 2016 г. характеризовалась мезотрофным состоянием, то на востоке преобладал олиготрофный тип вод. С этим согласуется и характер распределения метазойного зоопланктона, играющего существенную роль в питании планктоноядных желетелых, с максимумом в районе западного побережья и более низкими значениями обилия в южных и юго-восточных (отчет 84-го рейса). Возможно, различия в трофических условиях и были причиной различий в структуре популяции по районам.

В весенние месяцы, как зимой, три других вида желетелых составляли незначительную долю общей биомассы сообщества хищных желетелых.

Размерная структура популяции M. leidyi в период наблюдений сохраняла зимний характер, когда популяция представлена прошлогодними крупными особями. Интенсивное размножение еще не началось из-за низкой температуры воды. Оптимальная температура для размножения M. leidyi выше $20{ }^{\circ} \mathrm{C}$ (Finenko et al., 2009).

Возможно, популяция $B$. ovata в Евпаторийско-Севастопольском регионе c мелкими неполовозрелыми животными представляет остатки прошлогодней генерации, так как низкая численность M. leidyi в данный период не могла обеспечить его рост: как правило, в массовом количестве он появляется после вспышки мнемиопсиса (Finenko et al., 2006).

Полученные показатели развития желетелого макропланктона свидетельствуют о существовании различий в его структуре и количественном развитии у южного и западного побережий Крыма: в Каркинитском заливе наблюдались минимальные биомассы всех видов желетелых с преобладанием мелких особей в популяции, в то время как в районе Южного берега Крыма - максимальные с доминированием крупных животных.

Время полужизни зоопланктона показывает, как долго (в днях) требуется популяции 
хищника, чтобы снизить популяцию жертвы на 50 \%. Преимущество этого показателя в том, что он позволяет сравнивать эффект популяции хищников с разной численностью. A. aurita питается, главным образом, зоопланктоном и в некоторые периоды года во фьордах и прибрежных областях контро- лирует биомассу зоопланктона (Hanson et al., 2005; Møller and Riisgård, 2007; Riisgård et al., 2010). В прибрежных районах Черного моря у берегов Крыма весной 2016 г. пресс желетелых на мезозоопланктон был слабым и не приводил к кардинальному сокращению численности зоопланктона.

\section{Список литературы / References}

Аболмасова Г.И., Финенко Г.А., Романова 3.А., Дацык Н.А., Аннинский Б.Е. (2012) Состояние желетелого макрозоопланктона в шельфовой зоне крымского побережья Черного моря в 2009-2010 гг. Морской экологический журнал, 11(3): 17-24 [Abolmasova G. I., Finenko G.A., Romanova Z.A., Datsyk N.A., Anninsky B.E. (2012) State of gelatinous macrozooplankton in inshore waters off Crimean coast of the Black Sea in 2009-2010. Marine Ecological Journal [Morskoi ekologicheskii zhurnal], 11(3): 17-24 (in Russian)]

Аннинский Б.Е., Аболмасова Г.И., Дацык Н.А. (2011) Влияние желетелых хищников на кормовую базу мелких пелагических рыб. Выедание мезозоопланктона медузой Aurelia aurita L. в Черном море. Промысловые биоресурсы Черного и Азовского морей. Еремеев В.Н., Гаевская А.В., Шульман Г.Е., Загородняя Ю.А. (ред.) ЭКОСИ Гидрофизика, Севастополь, c. 276-283 [Anninsky B.E., Abolmasova G. I., Datsyk N. A. (2011) Effect of gelatinous predators on forage reserve of small pelagic fish. Consumption of mesozooplankton by jellyfish Aurelia aurita L. in the Black Sea. Biological resources of the Black Sea and Sea of Azov. Eremeev V.N., Gaevskaya A. V., Shulman G. E., Zagorodniaya Yu.A. (eds.) EKOSI Gidrofizika, Sevastopol, p. 276-283 (in Russian)]

Водяницкий В.А. (1949) О естественноисторическом районировании Черного моря, и в частности у берегов Крыма. Труды Севастопольской биологической станции. Том 7. М., Л., Издательство АН СССР, с. 249-255 [Vodyanitskii V.A. (1949) On natural - historical zoning of the Black Sea and, particularly, off Crimea coast. Proceedings of the Sevastopol biological station. Vol. 7. Moscow, Leningrad, Publishing House AS USSR, p. 249-255 (in Russian)]

Петипа Т. С. (1957) О среднем весе основных форм зоопланктона Черного моря. Труды Севастопольской биологической станции. Том 9. М., Л., Издательство АН СCCP, с. 39-57 [Petipa T. S. (1957) On the mean weight of basic zooplankton forms of the Black Sea. Proceedings of the Sevastopol biological station. Vol. 9. Moscow, Leningrad, Publishing House AS USSR, p. 39-57 (in Russian)]

Финенко Г.А., Романова 3.А., Аболмасова Г.И., Аннинский Б.Е., Губарева Е.С., Бат Л., Кидейс А. (2005) Влияние условий питания на скорость потребления и переваривания пищи у лопастного гребневика Mnemiopsis leidyi. Морской экологический журнал, 4(1): 75-83 [Finenko G. A., Romanova Z. A., Abolmasova G. I., Anninsky B. E., Gubareva E. S., Bat L., Kideys A. (2005) Effect of food conditions on ingestion rate and digestion time in lobate ctenophore Mnemiopsis leidyi. Marine Ecological Journal [Morskoi ekologicheskii zhurnal], 4(1): 75-83 (in Russian)]

Финенко Г.А., Аболмасова Г.И., Романова 3. А., Дацык Н. А., Аннинский Б.Е. (2011) Влияние желетелых хищников на кормовую базу мелких пелагических рыб. Современное состояние популяции гребневиков Mnemiopsis leidyi как пищевых конкурентов промысловых рыб в прибрежных районах крымского побережья Черного моря. Промысловые биоресурсы Чер-

$$
-179-
$$


ного и Азовского морей. Еремеев В.Н., Гаевская А. В., Шульман Г.Е., Загородняя Ю. А. (ред.) ЭКОСИ Гидрофизика, Севастополь, с. 271-276 [Finenko G. A., Abolmasova G. I., Romanova Z. A., Datsyk N. A., Anninsky B.E. (2011) Effect of gelatinous predators on forage reserve of small pelagic fish. Up-to-date state of ctenophore Mnemiopsis leidyi population as food competitors of commercial fish in inshore areas off Crimean coast of the Black Sea. Biological resources of the Black Sea and Sea of Azov. Eremeev V.N., Gaevskaya A.V., Shulman G.E., Zagorodniaya Yu.A. (eds.) EKOSI Gidrofizika, Sevastopol, p. 271-276 (in Russian)]

Финенко Г. А., Дацык Н. А., Аннинский Б. Е. (2016) Пространственное распределение и питание желетелых хищников в прибрежных районах Крыма в зимний период 2016 г. Морской биологический журнал, 1(3): 42-49 [Finenko G.A., Datsyk N.A., Anninsky B.E. (2016) Spatial distribution and feeding rate of gelatinous predators in inshore areas of Crimean Coast in winter 2016. Marine Biological Journal, 1(3): 42-49 (in Russian)]

Anninsky B.E., Finenko G.A., Abolmasova G.I., Hubareva E. S., Svetlichny L. S., Bat L., Kideys A.E. (2005) Effect of starvation on the biochemical compositions and respiration rates of ctenophores Mnemiopsis leidyi and Beroe ovata in the Black Sea. Journal of the Marine Biological Association of the United Kingdom, 85: 549-561

Anninsky B.E. (2009) Organic composition and ecological energetics of the jellyfish Aurelia aurita L. (Cnidaria, Scyphozoa) under Black Sea conditions. Trophic relationships and food supply of heterotrophic animals in the pelagic ecosystem of the Black sea. Shulman G. E., Öztürk B., Kideys A.E., Finenko G. A., Bat L. (eds.) Istanbul, Turkey, Black Sea Commission Publications, p. 99-160

Datsyk N.A., Finenko G. A., Abolmasova G.I. (2016) Jellyfish zooplankton in the coastal and open regions of the Black Sea in spring 2013. Hydrobiological Journal, 52(1): 29-39

Finenko G.A., Romanova Z.A. (2000) Population dynamics and energetics of ctenophore Mnemiopsis leidyi. Oceanology, 40(5): 677-685

Finenko G. A., Romanova Z.A., Abolmasova G.I., Anninsky B.E., Pavlovskaya T.V., Bat L., Kideys A. (2006) Ctenophores - invaders and their role in the trophic dynamics of the planktonic community in the coastal regions off the Crimean Coasts of the Black Sea (Sevastopol Bay). Oceanology, 46(4): 472-482

Finenko G. A., Anninsky B.E., Abolmasova G. I., Romanova Z.A., Bat L., Kideys A.E. (2009) Functional role of the ctenophore invaders Mnemiopsis leidyi Agassiz and Beroe ovata Mayer in inshore planktonic communities. Trophic relationships and food supply of heterotrophic animals in the pelagic ecosystem of the Black Sea. Shulman G.E., Öztürk B., Kideys A. E., Finenko G. A., Bat L. (eds.) Istanbul, Turkey, Black Sea Commission Publications, p. 161-221

Finenko G.A., Anninsky B.E., Datsyk N.A. (2018) Mnemiopsis leidyi A. Agassiz, 1865 (Ctenophora: Lobata) in the inshore areas of the Black Sea: 25 years after its outbreak. Russian Journal of Biological Invasions, 9(1): 86-93

Hansson L.J., Moeslund O., Kiorboe T., Riisgard H.U. (2005) Clearance rates of jellyfish and their potential predation impact on zooplankton and fish larvae in a neritic ecosystem (Limfjorden, Denmark). Marine Ecology Progress Series, 304: 117-131

Møller L.F., Riisgard H.U. (2007) Feeding, bioenergetics and growth in the common jellyfish Aurelia aurita and two hydromedusae Sarsia tubulosa and Aequorea vitrina. Marine Ecology Progress Series, 346: 167-177 
Purcell J.E., Uye S., Lo W.T. (2007) Anthropogenic causes of jellyfish blooms and direct consequences for humans: a review. Marine Ecology Progress Series, 350: 153-174

Purcell J.E. (2012) Jellyfish and ctenophore blooms coincide with human proliferations and environmental perturbation. Annual Review of Marine Science, 4: 209-235

Richardson A.J., Bakun A., Hays G.C., Gibbons M.J. (2009) The jellyfish joyride: causes, consequences and management responses to a more gelatinous future. Trends in Ecology \& Evolution, 24(6): 312-322

Riisgard H. U., Barth-Jensen C., Madsen C.V. (2010) High abundance of the jellyfish Aurelia aurita excludes the invasive ctenophore Mnemiopsis leidyi to establish in a shallow cove (Kertinge Nor, Denmark). Aquatic Invasions, 5(4): 347-356 